\title{
The crisis of patient-physician trust and bioethics: lessons and inspirations from China
}

\section{Citation}

Nie, Jing-Bao, Lun Li, Grant Gillett, Joseph D. Tucker, and Arthur Kleinman. 2017. "The Crisis of Patient-Physician Trust and Bioethics: Lessons and Inspirations from China." Developing World Bioethics (September 18). Portico. doi:10.1111/dewb.12169.

\section{Published Version}

doi:10.1111/dewb.12169

\section{Permanent link}

http://nrs.harvard.edu/urn-3:HUL.InstRepos:34334600

\section{Terms of Use}

This article was downloaded from Harvard University's DASH repository, and is made available under the terms and conditions applicable to Open Access Policy Articles, as set forth at http:// nrs.harvard.edu/urn-3:HUL.InstRepos:dash.current.terms-of-use\#OAP

\section{Share Your Story}

The Harvard community has made this article openly available.

Please share how this access benefits you. Submit a story.

\section{Accessibility}




\title{
TOWARD A TRUST-ORIENTED BIOETHICS: LESSONS AND INSPIRATIONS FROM CHINA
}

Jing-Bao Nie, Lun Li, Grant Gillett, Joseph T. Tucker, and Arthur Kleinman

\section{Correspondence:}

Jing-Bao Nie, Bioethics Centre, University of Otago, 71 Frederick St., Dunedin, New Zealand; email: jing-bao.nie@,otago.ac.nz.

\begin{abstract}
Trust is indispensable not only for interpersonal relationships and social life, but for good quality healthcare. As manifested in the increasing violence and tension in patient-physician relationships, China has been experiencing a widespread and profound crisis of patient-physician trust. And globally, the crisis of trust is an issue that every society, either developing or developed, has to face in one way or another. Yet, in spite of some pioneering works, the subject of patient-physician trust and mistrust -- a crucial matter in healthcare especially because there are numerous ethical implications -- has largely been marginalized in bioethics as a global discourse. Drawing lessons as well as inspirations from China, this paper demonstrates the necessity of a trust-oriented bioethics and presents some key theoretical, methodological and philosophical elements of such a bioethics. A trust-oriented bioethics moves beyond the current dominant bioethical paradigms through putting the subject of trust and mistrust in the central agenda of the field, learning from the social sciences, and reviving indigenous moral resources. In order for global bioethics to claim its relevance to the things that truly matter in social life and healthcare, trust should be as vital as such central norms like autonomy and justice and can serve as a potent theoretical framework.
\end{abstract}

\section{KEW WORDS}

China, trust, patient-physician relationship, healthcare, trust-oriented bioethics, global bioethics 
The theme of this special issue is "Rebuilding patient-physician trust in China, Developing a trust-oriented bioethics." Utilising a methodology that integrates anthropological and sociological inquiry with ethical analysis, the previous articles have investigated the phenomenon and sources of patient-physician mistrust and the mechanisms required to rebuild a trust in the healthcare system in mainland China. Drawing lessons as well as inspirations from China, in this paper we argue for the necessity of a trust-oriented bioethics and outline the theoretical and methodological foundations of such a bioethics. By so doing, this paper addresses specifically the second main aim of this thematic issue.

"People cannot stand without trust," as Confucius asserted 2600 years ago in one of his best-known statements, recorded by his disciples in Lunyu (The Analects) (Book XII: 7). Among other things, this means that if trust is absent, neither individual life nor local communities and the wider society can thrive or even survive. The central thesis of this paper (and the entire thematic issue) is that, to paraphrase Confucius, medicine cannot stand without mutual trust between patients and their relatives, on the one side, and health professionals and institutions on the other. And neither can bioethics in China and around the globe stand upright without placing trust in its central agenda.

\section{PATIENT-PHYSICIAN MISTRUST IN CHINA: CONSEQUENCES AND CONTEXT}

China, the world's most populous country where more than 1.3 billion people live, has been experiencing an extensive and profound crisis of patient-physician trust over the past two or so decades. As other articles in this issue have demonstrated, numerous ethical lessons can and should be learnt from China's experience. For the purpose of articulating the key elements of a trust-oriented bioethics, here let us highlight three points: first, patient-physician mistrust has grave consequences; second, mistrust is manifested in the broader social context; and third, the crisis of patient-physician trust is at heart a crisis of values.

The epidemic of mistrust in Chinese healthcare has a variety of symptoms, both immediate and far-reaching. Among salient ones is that not only verbal abuse and humiliation but 
acts of physical violence directed against medical professionals by aggrieved and angry patients and their relatives are becoming increasingly commonplace in China ${ }^{1}$. Surveys of health professionals confirm that widespread "medical violence" exists on a nationwide scale. A national survey carried out in 2008 showed that $3.9 \%$ of medical professionals reported having been physically assaulted within the past year and almost $50 \%$ had been verbally abused. ${ }^{2}$ National surveys conducted by the Chinese Medical Doctor Association in 2009, 2011 and 2014 indicated that incidents in which the doctors surveyed were injured, sometimes seriously, as the result of medical violence had escalated over time; the 18 incidents reported in 2009 had risen to 149 in 2014, an almost eight-fold increase over five years. ${ }^{3}$ The 2014 survey shows that the majority (60\%) of medical professionals surveyed had experienced verbal abuse from patients and relatives and that $13 \%$ had been physically assaulted and harmed.

Neologisms such as "yiliao baoli" (medical violence) and "yinao" (medical mobs, medical fracas) have entered the Chinese language and are often used in the mass media, social media and academic publications when discussing healthcare issues. "Yinao" refers to the novel phenomenon of "medical mobs" involving patients, their relatives and supporters gathering, usually in hospital settings, to demand financial compensation and public apologies for alleged misconduct by health professionals or officials. This practice has become so widespread that in April 2012 the Ministry of Health and the Ministry of Public Security jointly issued a special

1 E.g. Hesketh T, Wu D, Mao L Ma N. Violence against Doctors in China. British Medical Journal 2012; 345: e5730; Liebman B. Malpractice Mobs: Medical Dispute Resolution in China. Columbia Law Review 2013; 113: 181-264; Tucker JD, Cheng Y, Wong B, Gong N, Nie JB, Zhu W, ... Kleinman A, the Patient-physician Trust Project Team. 2015. Patient-physician mistrust and violence against physicians in Guangdong Province, China: a qualitative study. BMJ Open 2015;5:e008221.doi:10.1136/bmjopen2015-008221.

2 Zhang X, Sleeboom-Faulkner M. Tension between Medical Professionals and Patients in Mainland China. Cambridge Quarterly of Healthcare Ethics 2011; 20: 458-465.

3 Chinese Medical Doctor Association (CMDA). White Paper on the State of the Medical Profession in China. at http://www.cmda.net/xiehuixiangmu/falvshiwubu/tongzhigonggao/2015-05-28/14587.html; 2015. Accessed on July 30, 2016. 
proclamation aimed at maintaining order in medical institutions. The document emphasized that those charged with enforcing public security would take stringent measures against anyone assaulting or otherwise perpetrating violence against medical professionals. In 2015, measures to combat "medical mobs" and attacks on medical professionals were added to the Chinese criminal law code.

The most disturbing aspect of this increasingly violent patient-physician relationship is patients murdering health professionals. One such case involved a well-known specialist at a major hospital in southern inland China who offered an innovative treatment regime combining biomedical intervention with traditional Chinese remedies for leukemia. Motivated by public medical advertisements, a well-educated 38-year-old male patient suffering from leukaemia began seeing this physician, with high expectations of a cure. However, following several months of treatment, his health continued to deteriorate, and he had spent almost all of his and his family's savings to pay for treatment. The frustrated patient subsequently killed his 67-yearold physician on a road on the hospital grounds. After stabbing the physician 46 times, he sat on the roadside and requested passers-by to call the police. When the police arrived to arrest him, he muttered "No hurry - let me wash my hands first", while repeatedly making the victory sign to bystanders. One month later, the patient was convicted of murder and sentenced to death. The murdered physician was posthumously awarded the title of "The People's Good Doctor" by the hospital and higher healthcare authorities. During this period, another physician in the same hospital committed suicide, allegedly as a result of poor patient-physician relationships and a dysfunctional work environment.

The specialist's murder, which occurred in 2001, was widely reported by the Chinese mass media. The case, which appeared at the time to be an isolated one, was in fact part of a general trend towards an increasingly violent patient-physician relationship in Chinese society. The same year, another dissatisfied patient planted a bomb in a hospital in Chongqing, causing five deaths and dozens of injuries. Since then, many highly publicized cases of killing or seriously injuring health professionals have been reported each year throughout China. Since 2012, they have included the following incidents: 
2012, in Chaozhou, a patient killed the vice-president of a hospital and seriously injured two other staff; in Hengyang, a physician was killed by her patient; in Harbin, a 17-yearold patient killed one medical professional and seriously injured another; in Tianjin, a patient killed another patient; in Beijing, a physician was seriously injured by her patient;

2013, in Baotou, a physician was murdered by her patient;

2016, in Guangzhou, a patient stabbed his dentist to death while demanding compensation for allegedly incompetent treatment performed more than two decades earlier; in Hunan, an otolaryngologist (an ear, nose and throat specialist) died after incurring serious injuries at the hands of his aggrieved patient's relatives.

All these cases constitute a far cry from a general context in which patients and doctors are expected to develop a partnership of care and the doctor should be a person who helps support the patient by being someone whom the patient can lean on in their health care journey. ${ }^{4}$

The patient-physician relationship should not be defined as merely a relation between individual patients and health professionals, but must be seen as a part of broader social relationships. The rapidly increasing incidence of medical conflict and violence against health professionals in China reflects a larger trend that raises fundamental questions about patientphysician trust. Violence against medical professionals is only one manifestation of the scale of the crisis of medically related trust and the much larger crisis of social trust in general in contemporary China.

A number of factors influence patient-physician trust (and its deterioration) in the Chinese context. The marketization of healthcare has had a number of negative consequences including truncated consultation times, a reduced focus on caregiving, and the increasing influence of pharmaceutical representatives in clinical encounters. Questions of social status, the practice of gifting or bribing doctors with "red envelopes" (monetary presents), poor communication, and inadequate medical training in the areas of ethics and professional development all have the potential to undermine the relationship between patients and their

${ }^{4}$ Gillett G. Bioethics in the Clinic. Baltimore: Johns Hopkins UP; 2004. 
physicians. Relatively weak legal mechanisms in Chinese society for resolving disputes often give patients and physicians limited options when conflict arises. Unintended consequences of patient-physician mistrust, such as sensational media reporting and an increased police presence in hospitals, no doubt serve to spur further tensions between patients and medical professionals. All these factors have contributed to what we have called the vicious circle of patient-physician mistrust.

The current crisis of patient-physician trust constitutes part of the massive series of transformations (social, economic, political and cultural) that China has undergone over the past three or four decades. In the late 1970s and early 1980s, China initiated the revolutionary social policies centered on "reform and openness" and "economic development" with tremendous immediate and far-reaching impacts upon not only Chinese society, but the whole world. Since then, China has offered the world a story of remarkable success, including rapid and continuous economic growth, dramatic improvements in living standards and healthcare, wholesale urbanization, major advances in science and technology, and an increasingly active role in global affairs. However, the dark side of China's great success story is no less remarkable, including the increasing gap between the rich and the poor, environmental destruction, enormous social suffering, increasing conflict between the government and the people and between different social groups, and the spread of violence in society. In addition, both individually and collectively, Chinese people are involved in unprecedented yet everyday "quests for meaning", including the search for justice, happiness, respect, gender equality, religious beliefs, and doing good in a not-so-good world. ${ }^{5}$ Patient-physician mistrust in China should be seen in the broad context of this grand modern odyssey as it unfolds in the ever-changing domestic and global environments.

The crisis of patient-physician trust is itself part of a much wider crisis of values, social and health institutions, and social trust in Chinese society. Thus, widespread and profound patient-physician mistrust is severely damaging, not only in the instrumental sense (as it leads to poor healthcare outcomes) but, more importantly, in the intrinsic sense (as it threatens basic

5 Kleinman A, Yan Y, Jun J, Lee S, Zhang E, Pan T, Wu F, Guo J. Deep China: The Moral Life of Person. ? title?? Berkeley: University of California Press; 2011. 
social, ethical and existential values). Rebuilding patient-physician trust would therefore serve not only to improve interpersonal relationships in the healthcare system, but also to restore endangered or lost values that are nevertheless essential to the health of Chinese society. These values include humaneness, righteousness, justice, trustworthiness, medicine as the art of humanity that underscoring community or the need to support one another on the journey of illness and life.

\section{THE CRISIS OF TRUST: A GLOBAL ISSUE}

The contemporary crisis of trust in the area of healthcare is not a problem that China faces alone. Rather, it is a global issue. Also, this crisis of trust is not limited to healthcare, but affects almost every area of social, economic, political and cultural life. Moreover, the issue of trust - or the lack of it - is always a basic factor in international affairs and interstate relationships. In the Western context, it was long noted that the expression "loss of trust" has become a cliché of our times. ${ }^{6}$ In the political sphere, numerous recent major events such as Brexit and the Trump presidency - the tiny tip of an iceberg - illustrate the truth of this all-toofamiliar observation. In the medical sphere, there has been a general decline of trust by patients in their physicians and the healthcare system in the U.S. and other Western countries. ${ }^{7}$

Patient-physician mistrust has also been emerging as a major problem in many nonWestern countries. For example, India, the world's second most populous country, has undergone a massive erosion of trust in the medical profession in recent years. ${ }^{8}$ The medical profession and healthcare institutions in India are in a protracted state of crisis due to this

6

O’Neil O. A Question of Trust (The BBC Reith Lectures). Cambridge: Cambridge UP; 2002: 9.

7 E.g. Imber JB. Trusting Doctors: The Decline of Moral Authority in American Medicine, Princeton: Princeton UP; 2008; Pilgrim D, Tomasin F, Vassilev I. Examining Trust in Healthcare: A Multidisciplinary Perspective. New York: Palgrave Macmillan; 2011.

${ }^{8}$ Kane S, Calnan M. Erosion of trust in the medical profession in India; the time for doctors to act. International Journal of Health Policy and Management 2016; doi10.15171/ijhpm.2016.143. 
betrayal of trust, which has been caused by multiple factors including corruption, professional negligence, accepting kickbacks and illegal dual practice arrangements. While trust is a cornerstone of the patient-physician relationship and strongly related to patient satisfaction, little research has been carried out on patient-physician trust in India and the developing world. ${ }^{9}$

There is plenty of evidence to support the global scale of patient-physician mistrust. However, the extent of the problem may well differ dramatically from one country to another. At present, systematic transnational comparative studies are lacking. Based on our own experience and research, it is fair to assert that the crisis of patient-physician trust in China is far more serious than in most other parts of the world, especially developed countries. For instance, although the issue of trust is (and should be) a serious concern in New Zealand, ${ }^{10}$ patientphysician relationships there are markedly better than in China. Furthermore, while acts of violence and abuse against health professionals by patients and their relatives occur everywhere, those observed from China in recent years look to be more frequent and severe compared to many other countries.

\section{TRUST MARGINALIZED IN GLOBAL BIOETHICS}

The essential role of trust in maintaining social relations, of which healthcare forms a part, is analogous to the way that air supports life. And trust is indispensable in the provision of adequate healthcare from the outset of an illness journey (when the doctor must be trusted to do the right investigations and draw on an adequate body of medical knowledge to its conclusion (particularly when that involves palliative care or significant uncertainty). As a result, the subject of trust should have been a prominent focus of research for bioethics. This, however, is not the case at all. As late as the early 2000s, a British philosopher-bioethicist pointed out that "there has been less discussion of trust and loss of trust in bioethics, or in ethics more generally, than one

9 Gopichandran V, Chetlapalli SK. Factors influencing trust in doctors: a community segmentation strategy for quality improvement in healthcare. BMJ Open 2013; 3:e004115.

10 Henaghan M. Health Professionals and Trust: The Cure for Healthcare Law and Policy. London: Routledge; 2011. 
might have expected". ${ }^{11}$ The Cinderella status of the subject in bioethics remains basically unchanged today.

It is not that the topic of medical trust and mistrust has been totally overlooked in bioethics. There exist pioneering scholarly works that address practical and theoretical challenges in bioethics from the angle of trust. In research ethics, probably the best developed subfield of contemporary bioethics, a series of publications have identified and investigated the critical but fragile role of trust in clinical research relationships, related normative issues such as moral obligations of the state, the perspectives of research participants, and issues in international (e.g. African and German) settings. ${ }^{12}$ Based on an empirical study in Kenya, scholars proposed "an inner generated ethics of service" founded upon trust and a healthy mistrust which is too fundamental to be governed effectively merely through guidelines, polices and the laws that currently regulate the practice of biomedical research. ${ }^{13}$ They also observed: "Trust is an important theme running through the literature on the ethics of biomedical research, but it is rarely given central stage."14

In her influential book, Autonomy and Trust in Bioethics, British philosopher Onora O’Neill has explored such issues as the quest for trustworthiness, displaced trust and mistrust,

11 O’Neill O. Autonomy and Trust in Bioethics. Cambridge: Cambridge UP; 2002: 12.

12 E.g. Kass N, Sugaman J, Faden R, Schoch-Spana M. Trust: The Fragile Foundation of Contemporary Biomedical Research. Hastings Center Report 1996; 26(5):25-29; Miller PB, Weijer C. Trust based obligations of the state and physician-researchers to patient-subjects. Journal of Medical Ethics 2005; 32: 542-547; McDonald M, Townsend A, Cox SM, Paterson D, Lafreniere. Trust in Health Research Relationships: Accounts of Human Subjects. Journal of Empirical Research on Human Research Ethics 2008; 3: 35-47; Tindana PO, Kass N, Akweongo P. The Informed Consent Process in a Rural African Setting. IRB: Ethics \& Human Research 2006; 28:1-6; Nibile H, Bergmann, MM, Moldenhauer J, Borry P. Participants Accounts on Their Decision to Join a Cohort Study with an Attached Biobank: A Qualitative Content Analysis Study within Two German Studies. Journal of Empirical Research on Human Research Ethics 2016; 11(3):237-249.

13 Molyneux CS, Peshu N, Marsh K. Trust and informed consent: insights from community members on the Kenyan coast. Social Science and Medicine 2005; 61: 1463-1473.

14 Ibid: 1463. 
and trust and the media, all in a bioethical context. ${ }^{15}$ Nevertheless, O'Neill's aim is to offer not so much a philosophical framework for a trust-centered bioethics as a critique of the impoverished understanding of autonomy in mainstream bioethics as employed by both academia and the mass media. With another British philosopher Neil Manson, O'Neil has further addressed the issue of trust in a chapter in the book, Rethinking Informed Consent in Bioethics. Yet, again, their central aim is not to investigate medical trust and mistrust per se but to expose the theoretical and practical problems of the standard account of informed consent in biomedical research and healthcare and the philosophical arguments involved, and to propose an alternative centered on "information transactions". ${ }^{16}$

As for trust and bioethics in the Chinese context, a few studies published in English have examined the role of medical professionalism (particularly the need for a fiduciary model) ${ }^{17}$ and reported the results of a nationwide survey on violence against medical professionals ${ }^{18}$. In the edited volume, China: Bioethics, Trust, and the Challenge of the Market, Julia Tao (a philosopher-bioethicist in Hong Kong) and her Chinese and international collaborators investigated the effects and ethical issues surrounding market-oriented healthcare reforms in China. ${ }^{19}$ Nevertheless, while Tao's brief introduction is entitled "The bioethics of trust", little is presented in the book about what such a bioethics might involve. And there is little specific discussion of how market-oriented healthcare reforms have fundamentally undermined patients' trust in health professionals and healthcare institutions but such changes do introduce commercial conflicts of interest into clinical relationships.

15 O’Neill, op. cit. note 11.

16 Manson NC, O’Neill O. Rethinking Informed Consent in Bioethics. Cambridge: Cambridge UP; 2007.

17 Hui, EC. The Contemporary Healthcare Crisis in China and the Role of Medical Professionalism. Journal of Medicine and Philosophy 2010; 35:477-492.

18 Zhang, Sleeboom, op. cit. Note 2.

19 Tao J, editor. China: Bioethics, Trust, and the Challenge of the Market. Berlin: Springer; 2008. 
A major subfield in contemporary bioethics is concerned with the professional ethics of medicine and the patient-physician relationship. Because of its obvious importance to the patient-physician relationship - indeed any interpersonal relationship - it is hard to understand why the issue of trust and mistrust constitutes the focus of only scant bioethical studies to date ${ }^{20}$ Historically, influential statements such as the Hippocratic Oath from ancient Greece and (in the 20th century) the World Medical Association's Declaration of Medical Ethics have defined the professional ethics of medicine in the West. Mostly stemming from the Western medical and sociocultural context, a number of normative models of the patient-physician relationship have been advocated in contemporary bioethics, including the paternalistic, covenantal, contractual, humanistic, and fiduciary models. ${ }^{21}$ In its long and rich cultural history, China has also developed a series of norms for the professional ethics of medicine including the ideal of "medicine as the art of humanity" (yi nai renshu) and the principles expressed in Sun Simiao's Daoyi Jingcheng (The Absolute Sincerity of the Great Physician). ${ }^{22}$ Nevertheless, while promoting the trust of patients (and laypeople in general) in medical professionals may well be one of the underlying goals of these historical documents and contemporary models, none of them explicitly spells out the vital role of trust for the patient-physician relationship.

20 E.g. Pellegrino ED, Veatch RM, Langan JP. Ethics, Trust, and the Professions: Philosophical and Cultural Aspects. Washington DC: Georgetown UP; 1991; Hall M, Dugan E, Zheng B, Mishra AK. Trust in Physicians and Medical Institutions: What Is It, Can It Be Measured, and Does It Matter? The Milbank Quarterly 2001; 79(4): 613-639.

21 E.g. May W. The Physician's Covenant: Images of the Healer in Medical Ethics. Philadelphia: The Westminster Press; 1983; Veatch R. The Patient-Physician Relationship: The Patient as Partner. Bloomington: Indiana UP; 1991; Veatch R. Patient, Heal Thyself: How the New Medicine Puts the Patient in Charge. Oxford: Oxford UP; 2009.

22 E.g. Nie JB. The Discourses of Practitioners in China. in R. Baker and L. McCullough, editors. The Cambridge World History of Medical Ethics. New York: Cambridge UP; 2009: 335-344; Nie JB. Medical Ethics in China: A Transcultural Interpretation. London: Routledge; 2011; Unschuld P. Medical Ethics in Imperial China. Berkeley: University of California Press; 1997. 
The subject of medical trust and mistrust has, however, often been marginalized or even ignored in global bioethics. For example, in the World Medical Association's Declaration of Helsinki (1964, last updated in 2013) - in global terms, the most significant document for research ethics involving human participants and the issues around informed consent - trust is not mentioned at all, let alone featured as an important element. To cite another salient example, the UNESCO Universal Declaration on Bioethics and Human Rights (2005) is another landmark event in the recent history of international bioethics. The Declaration invokes a number of ethical principles which include human rights and human dignity, sharing benefits and the prevention of harm, autonomy and informed consent, respect for human vulnerability, justice and equity, respect for cultural diversity and pluralism, and solidarity and cooperation. However, once again, trust - considered at the interpersonal, societal and transnational levels - fails to rate a single mention in this influential document.

It can be concluded that bioethical studies and discussions conducted thus far on medical trust and mistrust in general, and the deteriorating patient-physician relationship in China in particular, are far from adequate. Perhaps one way to make sense of such an unfortunate intellectual failure to identify the elephant in the room of global bioethics is that trust - like the importance of air to life - is too obvious an element of social life and healthcare to be consciously recognized. In other words, like air to life, trust is too often taken for granted, and its vital role is rarely acknowledged and valued unless it is threatened or lost. In China, the subject failed to rate a significant place in academic circles and the public domain until the crisis of trust in healthcare escalated to its present level - a situation impossible to continue to ignore.

\section{A PHILOSOPHICAL ACCOUNT OF TRUST}

Similarly, the subject of trust has been by and large understudied in contemporary moral philosophy as undertaken in the Western world. However, there are exceptions. In the mid1980s, Annette Baier, a New Zealand philosopher then living in the US, opened up the philosophical discussion of trust. In a highly original essay entitled "Trust and Antitrust", Baier offered an astute and still valid diagnosis of the lack of attention in ethics paid to the subject, an analysis of the essential features of trust and the reasons for making trust a worthy topic for 
philosophical debate. ${ }^{23}$ She outlined a plausible framework within which to morally evaluate trust relationships.

Baier's diagnosis rests on the fact that "moral philosophy has concentrated on the morality of fairly cool relationships between those who are deemed to be roughly equal in power to determine the rules and to instigate sanctions against rule breakers". ${ }^{24}$ That framework enables devices such as the idea of a contract, the prisoners' dilemma, and explicit agreement to render the field of morality relatively "crisp" and the locus of explicit argumentation untrammeled by the vagaries and vicissitudes of human nature and interdependency, among which life must go on. The fact that power relationships can shift and vary, and are entwined with the details of intimacy and mutual dependence that influence our reactive attitudes, ${ }^{25}$ makes crispness, clarity and determinate reasoning less apt to do the work of understanding required. Here philosophy is on the shifting sands of second nature - our learning to live with one another and its genesis, rather than the sure foundations of a developed metaphysics.

Trust is analysed as “reliance on others' competence and willingness to look after, rather than harm, things one cares about". ${ }^{26}$ Trust is marked by inexplicit expectations and dynamic realities in which interpersonal attitudes and intersubjectivity have a role to play, and it forms a necessary element in the psychology of any surviving creature of a fragile type. Those who trust risk having their interests over-ridden but they know that they cannot do otherwise, because of the power and knowledge imbalances they are enmeshed in, nowhere more evident than in healthcare. Trust can be betrayed through incompetence, negligence or deliberate fault, but its acknowledgment as part of a relationship transforms such failings into morally significant features of the relationship concerned.

23 Baier A. Trust and Antitrust. Ethics 1986; 96(2): 231-260.

24 Ibid: 249.

25 Strawson FT. Freedom and resentment and other essays. London: Methuen; 1974.

26 Baier, op.cit. Note 23: 259. 
Trust can be morally and reasonably vindicated, or otherwise, and it rests on mutual goodwill. Baier suggested that morally commendable trust often begins inexplicitly and nonvoluntarily within an ethos where one has little choice. From those tentative beginnings, the doctor, as companion on the illness journey, enables trust to grow. The test of reasonableness is that the trust extended should survive an awareness or open knowledge of the reasons of both parties for entering the trust relationship, and that these should not involve motivations (such as threat and fear, exploitation, or over-dependence) that are themselves incompatible with virtue and the health of relationships. She also notes that an over-emphasis on a narrow two-person form of trust neglects the network of trust in which we are all implicitly involved (especially in healthcare) and the morality of brief trusting encounters where almost everything is implicit and situated. $^{27}$

Trust is fragile; it does not involve explicit duties and yet what it does involve is fairly clear to most human beings but its lack becomes starkly evident the moment it is betrayed. "Trust is often mixed with other forms of reliance on persons" ${ }^{28}$; it may rely on the other being willing to go further than one could explicitly demand of them in some matter, and to know how far is too far; it is difficult to create, hard to lose, and yet fragile in the face of bad faith. What is more, all of these things are given an immediacy when it is one's own health and well-being (or the health and well-being of loved ones) that is at stake in the ways that pervade medical care. The importance of these aspects of our humanity, therefore, makes a healthcare relationship one of the most crucial and vulnerable to acts which are deliberately, negligently or incompetently careless of what has been entrusted to one.

The illness journey in any place including China can be characterized as an extended locus of trust: intelligent listening and concern, careful diagnosis, conscientious treatment, responsive attention to the contingencies of a regimen of care, and non-abandonment are a sine qua non of ethical medicine and form a solid relational foundation for trust and trustworthiness. ${ }^{29}$

27 Ibid: $257-259$.

28 Ibid: 234.

29 Gillett, op. cit. Note 4. 
Where these things are part of our medical personae, patients are well served and where they are lacking doctors can become the foci of suspicion, resentment and criticism, all of which are justified. The ethos required by a well-functioning health system should, however, foster the conditions in which trust can reasonably thrive.

Bair's insightful ethical account of trust, validated in a painful way by the crisis of patient-trust in China, is meaningful in better understanding the Chinese crisis including why patients and their relatives have reacted so strongly and even violently when they feel their trust betrayed. More importantly, Baier's account calls for systematic and specific studies on many trust-related issues in the healthcare sector including why trust and trustworthiness become more important especially when one is more vulnerable due to illness and injuries and what this may entail in clinical practice. Above all, it urges that an examination and articulartion of trustoriented bioethics is long overdue within the intellectual endeavor of bioethics.

\section{DEVELOPING A TRUST-ORIENTED BIOETHICS: THREE ELEMENTS}

The principal ethical lesson to be learned from the Chinese crisis of patient-physician trust, or in the main, inspiration to be found in the Chinese experience, is that a trust-oriented bioethics is urgently needed in order for this academic field to become more relevant to what really matters in healthcare and social life. As we see it, such a bioethics would cover an extensive intellectual territory over which clinical life must range. While it is not possible to systematically chart it here, three general theoretical and methodological elements can be outlined.

\section{Putting Trust on the Central Agenda of Bioethics}

In his seminal book, Health Professionals and Trust, New Zealand legal scholar Mark Henaghan approaches health law and public policy in the NZ context from the perspective of trust and mistrust. The key question for his study is: "What would healthcare law and policy look like if it were driven by the central idea of establishing trust between healthcare professionals and their patients?" 30 Obviously, a similar question ought to be asked in relation to bioethics.

30 Henaghan, op. cit. Note 10: xi. 
Trust sustains interpersonal relationships and the social fabric in which all human beings are embedded. It is high time for bioethics to recognize the indispensable role of trust in the provision of adequate healthcare. Mutual trust establishes the context for honest communication, enabling physicians to elicit comprehensive medical histories and form culturally sensitive and nuanced personal relationships with the patients they serve. Trust in the context of a genuine partnership also provides the basis on which patients are able to fully understand and follow the recommendations of their physicians. Furthermore, trust is necessary for the voluntary participation of individuals and communities in medical research, without which healthcare services can hardly be improved.

Putting trust on the main agenda of bioethics will result in the reassessment of issues in the field that had hitherto been deemed as largely settled. For example, it may shed new light on the birth and development of contemporary bioethics itself as the critical study of a relationship rather than as the study of a kind of contract or set of duties framed by a calculus of benefit and harm. Historically speaking, the field as we know it today constitutes an intellectual response to social contexts and their failings such as those seen in wartime medical atrocities like Nazi medicine and Japan's medical experiments in China, as well as post-war scandals ranging from the Tuskegee syphilis experiments in the U.S. to the "Unfortunate Experiment" involving cervical cancer treatment at the National Women's Hospital in New Zealand. These notorious episodes were all ethically tainted insofar as they profoundly betrayed the trust of patients and the public in the medical profession and the drove bioethics towards a rights, conflict and duty based form of moral deliberation. If we question the light that this sheds on relationships of profound dependency, then major advances in bioethics will be accompanied by efforts to reestablish trust, relationship, and care as its basis.

Putting trust on the central agenda of bioethics will encourage us to rethink the dominant principles and theoretical frameworks of the field such as autonomy, informed consent and justice. Critically examined through the lens of trust and mistrust, these major bioethical norms will take on very different meanings. O'Neill's important book, Autonomy and Trust in Bioethics, sets out a case for the necessity and fruitfulness of such an examination. For O'Neill (2002b), the notion of trust has been marginalized in bioethics due to the dominance of the moral and political 
doctrine of autonomy in its excessively individualistic interpretation, issuing in negative healthcare and social consequences. To rectify this situation, a principled and relational understanding of autonomy based on Kant's non-individualistic moral and political theory is proposed as a better alternative. Feminism and feminist bioethics have also emphasized the need to appreciate and examine the role of care in bioethics and its inherent connection to situations where dependency is the norm and power may distort what is happening.

Moreover, the practical challenges of bioethics - such as informed consent and justice can be recast when viewed through the lens of patient-physician trust and mistrust. The principle of informed consent in healthcare and patients' rights in general have become increasingly accepted in China, and even demanded by patients. Nevertheless, genuinely shared decisionmaking based on effective informed consent must be founded on mutual trust between doctors and patients. To realize informed consent and other patients' rights in the Chinese health system, a culture of mutual patient-physician trust will need to be fostered. As the case of China illustrates, in addition to fostering inequality and injustice, mistrust constitutes a major source of inadequate healthcare. In order to improve healthcare services and address inequality in the health system, building patient-physician trust, not only in clinical encounters but also in a broader social context, is an imperative task. Justice in healthcare cannot be significantly advanced in reality without a robust culture of patient-physician trust and the appreciation that there is an enduring duty of care for those who need others to lean on in their illnesses.

\section{Learning from the Social Sciences}

The neglect of trust in the field of bioethics becomes even more unacceptable when compared to developments in the social sciences. Partly in response to the increasing mistrust shown by citizens in public figures as well as established social institutions, sociologists and political scientists have undertaken numerous studies to investigate what trust, mistrust and distrust mean for individuals and for social and political life. While this is not the place to present an overview of this large and growing body of literature, several points relevant to our stated aim of developing a trust-oriented bioethics should be made. 
First, the study of trust has become an important subfield of the contemporary social and political sciences, and trust has emerged as one of the key concepts for contemporary sociological inquiry. ${ }^{31}$ Trust has been recognized as an essential component of social capital and social virtue in terms of economic development, good governance and communal flourishing, providing a counterforce to the dominance of individualism. ${ }^{32}$ Second, there has been a shift of focus from individuals to social institutions. For instance, it is recognized that trust plays a vital role in political and civil life through sustaining and advancing positive relationships between citizens and the state. ${ }^{33}$ Third, transnational and transcultural comparisons are frequently made. It has been argued for example that, compared to "high-trust" countries such as the United States, Japan and Germany, China belongs to societies where the level of social trust is relatively low. ${ }^{34}$ Questions of trust and mistrust between nation-states have been approached from both the perspective of traditional political realism and the new game theory. ${ }^{35}$ Fourth, not only empirical studies, but also philosophical and ethical inquiries have been undertaken in this emerging subfield. Drawing on sociological data and insights, political scientists have made philosophically based efforts to examine the moral foundations of trust, and the fundamentally optimistic worldview on which trust depends. ${ }^{36}$

Because trust is by definition a social and relational phenomenon, a trust-oriented bioethics needs to learn from the social sciences. As the other papers in this thematic issue have shown, what the social sciences can offer to bioethics goes well beyond providing it with empirical information, however important this may be. More significantly, the social sciences are encouraging bioethicists to expand their intellectual horizons and to explore different approaches

31 E.g. Hardin R. Trust. In the "Key Concepts" Series. Cambridge: Polity; 2006; Hawley K. Trust: A Very Short Introduction. Oxford: Oxford UP; 2012.

32 E.g. Fukuyama F. Trust: The Social Virtues and the Creation of Prosperity. New York: Free Press; 1995.

33 Braithwaite V, Levi M, editors. Trust and Governance. New York: Russell Sage Foundation; 1998.

34 Fukuyama, op. cit. Note 29.

35 Kydd KN. Trust and Mistrust in International Relations. Princeton: Princeton UP; 2005.

36 Uslaner EM. The Moral Foundations of Trust. Cambridge: Cambridge UP; 2002. 
to bioethical questions. In addition, the social sciences have never been concerned merely with "facts," through objective or value-free empirical studies, but have historically been a part of the moral sciences. Among other things, these disciplines have treated the social dynamic underlying bioethical issues seriously and have integrated long-neglected but vital elements of social reality - such as trust - into inquiries with important bioethical implications.

The social sciences can offer effective antidotes to some powerful currents in bioethics such as "rugged individualism" and "thin universalism". Contemporary bioethics has been widely criticized for placing undue emphasis on the individual autonomy and rights as well as the assumption of the universal applicability of some overbearing ethical principles, resulting in a number of shortcomings. A leading field of inquiry in the social sciences examines the ways in which social institutions define and in many ways determine the wishes, choices and behaviours of individuals. One key finding of our research presented in this thematic issue is that the institutional flaws in the current Chinese health system constitute a major source of patientphysician mistrust. As a result, an exclusive focus on interpersonal clinical encounters - such as the communication skills of health professionals - will be insufficient in rebuilding this lost trust; China's flawed health and social institutions will have to be reformed as well.

There is a perennial tension in bioethics between universal or universalizable principles, on the one hand, and what has been named as "local moral worlds" on the other. The social sciences, especially anthropology, urge bioethicists to attend to complex, changing, diverse and divisive local worlds as well as to the rich moral experience of individuals. ${ }^{37}$ In face of this essential tension in bioethics, and human morality in general, the goal is not to discover a solution that holds good for all time, nor to justify everything that occurs in local worlds, but rather to reconcile these conflicting impulses in different contexts. Sociologically, through investigating the lived experiences and personal perspectives of Chinese patients and health professionals, our studies have led to novel understandings of the issues of mistrust, medical violence, and the distinctive socio-cultural phenomena of "red envelopes" (monetary gifts to physicians) and seeking healthcare through guanxi (personal connections). Ethically, our

37 Kleinman A. Moral Experience and Ethical Reflection: Can Ethnography Reconcile Them? A Quandary for "The New Bioethics. Daedalus 1999; 128: 69-97. 
research has identified elements that are morally problematic or tarnished in the everyday practice of healthcare in China.

\section{Reviving Indigenous Cultural Values}

Lastly, but not least importantly, a trust-oriented bioethics needs to call upon and revive the ideals, principles and wisdom inherent in indigenous moral and cultural traditions. This is a point that can never be overemphasized. Reflecting the Western domination of global economic, political and cultural life, a historical characteristic of our post-colonial times, bioethics has hitherto been dominated by the practical and theoretical concerns arising from the Western context. Because the enormous plurality and diversity of Chinese moral traditions is an essential feature of Chinese civilization, often downplayed or overlooked in the West as well as in China itself, it is necessary to point out that Chinese traditions include not only Confucianism, but also Daoism (Taoism), sinocized Buddhism, Christianity and Islam as practiced in China. All these moral and cultural traditions can contribute meaningfully to the development of a trust-oriented bioethics, both in China and, potentially, the rest of the world.

In developing a trust-oriented bioethics, it will be crucial to creatively engage with the rich intellectual resources of Confucianism. Julia Tao has drawn on Confucian moral and cultural values in an attempt to re-envision the ideal of trust across its various levels so that an ethically responsible private healthcare sector can be developed in partnership with an effective public system. $^{38}$ Generally speaking, xin (trust, trustworthiness, fidelity or truthfulness) constitutes one of the five key Confucian moral teachings, along with humaneness or humanity (ren), righteousness (yi), ritual (li) and wisdom (zhi) (Analects Book VII: 25). The Confucian notion of xin emphasizes the moral accountability of individuals in power and the health of the social institutions - including government - in which people invest their trust. Without trustworthiness, one cannot function as a person - just like a carriage which cannot be driven anywhere without the pin attaching the yoke to the oxen or horses pulling it (Book II: 20). For Confucius, the most vital ingredient of any good society is neither military power nor even economic development, but trust and trustworthiness. Trust or trustworthiness is more important than life itself. To cite

38 Tao, op. cit. Note 19. 
once again one of Confucius's household maxims, "While death has been omnipresent since ancient times, people cannot stand without trust" (Book XII: 7).

\section{CONCLUSIONS}

Without adequately addressing the matter of trust, bioethics - as an academic field, a public domain and a global discourse - can neither retain its present vitality nor develop in a healthy way for the future. In Confucian terms, it cannot stand. This is one of the major lessons to be learned from China. The global bioethics community cannot afford to take the example and message of China lightly, both in practice and in theory. Enormous social and personal costs, including the lives of many patients and health professionals, have already been paid as a result of neglecting patient-physician trust and the interdependency that defines all health care relationships. Meanwhile, the Chinese experience provides inspiration for the development of a trust-oriented bioethics in China as well as globally. Like autonomy and justice, trust should be a fundamental value of bioethics and can help provide a potent framework for the further development of the discipline as the ideal locus for the articulation of relationality as the ground on which our humanity rests.

Twenty-six centuries ago, in his major political and ethical work Chunqiu (Annals of Spring and Autumn), Confucius identified rapidly declining levels of trust as a defining characteristic of his own society. At the same time, through this succinct chronicle that is full of rich ethical and political implications, he powerfully illustrated the necessity - yet fragility - of trust and trustworthiness for healthy interpersonal relations and sociopolitical life to flourish. It is in this spirit that - as expressed at the end of our Editorial in this thematic issue - we urge that the profound and widespread crisis of trust in China and elsewhere in the world should not be treated as wholly negative, but as a unique opportunity to consciously rebuild patient-physician trust and foster a more trustworthy society and peaceful world through the development of a trust-oriented bioethics.

\section{BIOGRAPHIES}


Jing-Bao Nie, BMed, MMed, PhD, is Professor at the Bioethics Centre, University of Otago, New Zealand; Adjunct Professor at Peking University Medical School, China; and Associate of Harvard University Asia Centre, USA. His publications include Medical Ethics in China (Routledge, 2011) and a co-edited thematic issue on the methodologies of transcultural and global bioethics in Kennedy Institute of Ethics Journal (2016).

Lun Li, Ph.D., is Deputy Dean of School of Public Administration at Hunan Normal University, Changsha, China; and Professor of the Research Center for Moral Culture and Director of the Institute for Artificial Intelligence Moral Decision-Making, Hunan Normal University. His areas of research are bioethics, cyberethics and AI ethics. Email: lilun@hunnu.edu.cn.

Joseph D. Tucker, MD, PhD, AM is an Assistant Professor of Medicine at UNC Chapel Hill and Director of UNC Project-China. He co-leads a five-year research study on the social science and ethical implications of HIV cure research. He has a special interest in nurturing and instilling patient-physician trust in the Chinese context.

Grant Gillett, MB ChB, D.Phil (Oxon), FRS(NZ), is a Professor of bioethics at the University of Otago, Dunedin, New Zealand.

Arthur Kleinman, MD, MA, is professor of medical anthropology in the Department of Global Health and Social Medicine and professor of psychiatry at Harvard Medical School. He is the Esther and Sidney Rabb professor of anthropology in the Department of Anthropology in the Faculty of Arts and Sciences (FAS), and was the Victor and William Fung Director of Asia Center at Harvard University from 2008-2016. 